\title{
NEIBURG, Federico (Org.). 2019. Conversas etnográficas haitianas. Rio de Janeiro: Papéis Selvagens. 344pp
}

\author{
ALINE CORREIA ANTONINI \\ Universidade Federal do Mato Grosso do Sul, Campo Grande, Brasil \\ alinecorreiaantonini@gmail.com
}

DOI 10.11606/issn.2316-9133.v29i2pe176822

O Haiti está localizado na parte oeste da antiga ilha de Hispagniola, compartilhada com a República Dominicana ao leste, no Mar do Caribe. A independência nacional foi conquistada em janeiro de 1804, após uma revolução de escravizados. No dia 12 de janeiro de 2010, o país sofreu um sismo de 7 graus na escala Richter, que afetou mais de três milhões de pessoas, com consequências sem precedentes na história do país. Em 2012, o país foi atingido pelos furacões Isaac e Sandy e, em 2016, pelo furacão Matthew. É nesse contexto, anterior e posterior ao terremoto, que foram produzidas as pesquisas no Haiti que resultaram em dissertações, teses e em "Conversas Etnográficas Haitianas", obra aqui resenhada. Durante o mesmo período, meados do ano 2000, houve um crescimento na chegada de estrangeiros para residir no Brasil. Por razões diversas, os maiores grupos foram de haitianos, sírios e mais recentemente, venezuelanos. Ou seja, os dois maiores grupos são caribenhos.

Ademais, havia o incentivo e investimento financeiro nos programas de graduação e pós-graduação, possibilitando o impulsionamento nas etnografias realizadas nos países caribenhos. Esse campo da antropologia, os estudos caribenhos, em especial no Haiti, na fronteira com a República Dominicana e no Brasil, era até então pouco explorado por antropólogos brasileiros. Neste sentido, este livro surge em meio a um contexto de estímulos a pesquisa fora do Brasil, em que os antropólogos começaram a olhar para o Caribe, não quero dizer que nunca tenham olhado, mas que passaram a prestar atenção maior ao Caribe. Isso se traduz na quantidade expressiva de produções etnográficas e publicações de dissertações, teses e coletâneas de estudos caribenhos por antropólogos brasileiros, que anteriormente a este período dispunha de restrita produção sobre a região.

Lançado em 2019, Conversas Etnográficas Haitianas é uma coletânea preciosa, resultado de etnografias coletivas durante mais de uma década de pesquisa sobre e entre o Brasil e Haiti. Organizado pelo antropólogo Federico Neiburg, professor no Programa de Pós-Graduação em Antropologia Social do Museu Nacional, UFRJ. Desde 2007, coordena o Projeto Haiti, cujo objetivo principal é o entendimento das dinâmicas sociais no espaço 
nacional haitiano em perspectiva comparada. Todos os autores e autoras que compõem a coleção têm experiências de pesquisa no Haiti. Os capítulos são: "Sangue", de Louis Herns Marcelin; "Família", de Flávia Dalmaso; "Dinheiro", de Federico Neiburg; "Comércio", de Felipe Evangelista; "Frustração", de Pedro Braum; "Misturas", de José Renato Baptista; "Feitiço", de Ana Fiod; "Diáspora", de Handerson Joseph; "Ancestrais", de Rodrigo C. Bulamah; mais posfácio e apêndice.

Louis Herns Marcelin apresenta o capítulo "Sangue” como uma categoria analítica que ultrapassa a pertença da familiaridade e parentesco, atravessada por práticas culturais, políticas, religião, violência, nação, pessoas e magia. O autor ilumina "o simbolismo do sangue na criação do espaço haitiano de poder, privilégio e política” (:30). Essa simbologia é tão poderosa no Haiti que se transforma em um importante marcador entre a vida e a morte. O capítulo também inclui um diálogo potente com produções e autores pós-coloniais a partir da realidade social investigada pelo autor.

Flávia Dalmaso apresenta no capítulo "Família" uma conversa a partir da região de Gaston, sul do Haiti, entre discussões importantes sobre matrifocalidade, família e moradia, em que o sangue é um elemento substancial em todas. "Para meus interlocutores, o sangue é um elemento que produz semelhanças físicas, mas também de ordem moral entre as pessoas" (:66). Assim, entre traços que compõem a pessoa, é também através do sangue que são herdadas as terras, os antepassados mortos e os lwa (espíritos) que um dia pertenceram a um ancestral, geralmente conhecido como o fundador de uma determinada abitasyon (zonas de habitats dispersos) ou lakou (terreno).

No Haiti, além da circulação do gourde (moeda oficial) e do dólar estadunidense, há ainda uma moeda oral, sem existência física, conhecida como dólar haitiano. Neiburg apresenta, em "Dinheiro", que seu funcionamento se dá apenas como unidade de medida, em que um dólar haitiano equivale a 5 gourdes. Originalmente, o dólar haitiano circulava fisicamente em forma de moeda, oriunda do período colonial francês. Abolida, continuou a servir para contar dinheiro. Um exemplo apresentado por Neiburg em relação à taxa de conversão é dado a partir de uma negociação fictícia de um lote de mangas, no qual ambas as partes "concordam acerca do valor de 3 dólares haitianos; o comprador paga com uma nota de 50 gourdes (10 dólares haitianos); o vendedor fica com os 3 dólares do preço das mangas (15 gourdes) e dá como troco 7 dólares haitianos ( 35 gourdes, em três notas de dez e uma moeda de cinco)" (:81).

Felipe Evangelista aprofunda a conversa a partir do comércio, dinheiro e mobilidade no Plateau Central haitiano e na fronteira dominicana. Nos diz o autor, que o comércio é muito forte no Haiti. De certa maneira, tudo pode se transformar em mercadoria para "fazer comércio". Por exemplo, uma caixa de fósforo é dividida em partes de dez palitos e vendida separadamente para pessoas diferentes. É o fracionamento como forma possível de "fazer comércio". Ou seja, um pacote de cinco quilos de arroz é vendido por copos como unidade de medidas. Assim, concretizam-se as diferentes formas e dinâmicas de "fazer comércio". A partir do ponto de vista das mulheres, o autor revela que além do comércio ser o principal 
meio de provisão para si e seus dependentes, o "fazer comércio" pelas mulheres não é tido como um trabalho. A centralidade da discussão também é atravessada pela fronteira da afinidade entre comércio e mobilidade: "as comerciantes (machann) estão sempre em movimento, tanto entre as cidades e províncias haitianas quanto através de fronteiras internacionais” (:101) que são atravessadas por elas todos os dias.

Em "Frustração", Pedro Braum (:131) nos leva a Bel Air, maior bairro da capital haitiana, Porto Príncipe, onde na última década, houve uma proliferação de associações, comunidades e comitês, para organização e resistência frente às ações políticas de intervenção e às missões internacionais. $O$ texto é fundamental para compreendermos a relação entre a frustração, a violência, o entendimento local de confiança, interdependência, dever, respeito e vínculos. Principalmente, ao se considerar a dimensão histórica e política da grande região de Bel Air, que foi palco do mais sangrento ataque das tropas da Missão das Nações Unidas para Estabilização do Haiti (MINUSTAH) em 2005, na busca por lideranças combatentes na resistência aos abusos das tropas internacionais e interferência na deposição do presidente Jean Bertrand Aristide, também oriundo do bairro.

Em um universo de misturas religiosas, separá-las para pensá-las se torna uma tarefa difícil. Neste sentido, o antropólogo José Renato Baptista apresenta uma discussão estabelecida a partir do trânsito e experiências vividas entre e nos espaços das igrejas de $S t$. Anne, Des Ermites e ounfo (templo vodu). A primeira, uma igreja que é boate e também possui uma santa milagreira. A segunda, esteticamente se aproxima de uma igreja católica com seu altar de santos, ao mesmo tempo em que recebe e cultua o Iwa (espírito). Esta concepção de que a experiência fala em um universo onde "tudo está misturado" (:192) propõe que os princípios são ordenados em relação uns aos outros, definindo combinações e separações.

Ainda neste universo de práticas religiosas, Ana Fiod apresenta o feitiço a partir da agência das crianças na região sul do Haiti, no vilarejo de Siwvle que está localizado no departamento de Nippes. Apoiada nas dinâmicas de sociabilidades entre as crianças e adultos, familiaridades, vizinhança, ancestralidade e feitiços, a autora nos apresenta um universo de agências humanas e não humanas, bem como suas ambiguidades e correlações. Como a influência do lougawou (criaturas não humanas que se alimentam de humanos, especialmente de crianças) no processo de "pessoas pequenas" em adultos (:222). Ao observar os domínios dos lougawou, vem à tona o desenvolvimento das relações de adultos e crianças, de vizinhança e familiaridade, e toda uma dinâmica delicada que envolve acusações de feitiçaria diante da morte de uma criança sem explicação ou sem que ela esteja doente, rituais de proteção e reciprocidades. Assim, para além das experiências humanas e não humanas, essas são experiências de troca legítimas.

Na sequência, Handerson Joseph nos brinda com a nova geografia da diáspora haitiana na América do Sul. No entanto, diáspora, migração, refúgio são termos que atingiram o cerne de acalorados debates epistêmicos e disputas políticas, evidenciando as contradições e ambiguidades de práticas discursivas em torno do outro em movimento (seja ele imigrante, migrante e/ou refugiado). Neste cenário, os conceitos de migração e refúgio 
parecem não ser suficientes para dar conta dos aspectos e dimensões que envolvem o fenômeno da mobilidade e deslocamento de comunidades diaspóricas, como é o caso dos haitianos. É neste sentido que o trabalho de Handerson se torna a chave para compreender as dinâmicas desta mobilidade (:255). A diáspora haitiana se encaixa em um movimento muito maior, como o autor mostrou nos quatro grandes fluxos de mobilidade haitiana que iniciaram no ano de 1915. Segundo seus interlocutores, sair em diáspora não significa deixar o Haiti. Eles partem para o mundo em busca de melhores condições para si e para os que ficam, mas a casa é sempre o Haiti.

Convém lembrar que o Haiti foi profundamente estigmatizado em razão de ter sido a primeira nação das Américas liberta por negros de origem africana. Esta é uma questão essencial e fundamental. O Haiti paga uma dívida cara até hoje por ter se colocado contra as artimanhas coloniais de potências europeias. Os haitianos derrotaram o exército mais poderoso da época, o exército de Napoleão. Isso é importante para pensar a dimensão do abalo causado no mundo ocidental. Deste modo, a história, o passado, a cidadela, as ruínas e os ancestrais, suas conexões e pertencimentos, estão no eixo da etnografia de Rodrigo C. Bulamah, no vilarejo de Milot, região da planície norte do Haiti. Através das experiências de peregrinações, do andar e rodas de conversas, o espaço e o tempo se cruzam criando uma "intimidade histórica" (:286) que possibilita que as pessoas produzam seus conhecimentos atrelados a memória, ao parentesco e pertencimento, que se refazem como a própria nação.

Para encerrar, o livro nos fornece em apêndice um artigo produzido pela antropóloga Lygia Sigaud, por Omar Ribeiro Thomaz e por Federico Neiburg. A partir da experiência vivida em 2007 no Haiti, na ocasião do lançamento do Instituto Interuniversitário de Pesquisas e Desenvolvimento do Haiti (INURED), com cerca de 70 pesquisadores reunidos (:291), o texto tensiona a noção do lugar que ocupamos enquanto pesquisadores e os desafios de superarmos as ideias preconcebidas e colonialistas ainda existentes a respeito do Haiti, propondo a mudança para um olhar sobre nós mesmos num movimento novo de produção do conhecimento.

Durante os dois anos de pesquisa de campo, para o mestrado junto ao Programa de Pós-Graduação em Antropologia Social da Universidade Federal de Mato Grosso do Sul (PPGAS/UFMS), estabeleci diálogos com a Comunidade Haitiana na cidade de Campo Grande, capital do Mato Grosso do Sul. Nesse período tive dificuldades na busca por uma literatura antropológica que me possibilitasse pensar o campo. Minha experiência percorria os diferentes espaços ocupados pela comunidade, constituídos pela Associação HaitianoBrasileira (Ashabra), pelo diálogo com acadêmicos haitianos vinculados à UFMS e pelo frequentar das casas. A comunidade de haitianos existe desde 2013. Logo, esse livro contribuiu na construção da minha dissertação, assim como na minha formação enquanto pesquisadora, tornando-se o alicerce teórico para a compreensão de múltiplas formas de interação que revelam modos complexos e dinâmicos de produzir alianças, pertencimentos e diferenciações. 
Conversas Etnográficas Haitianas é uma leitura necessária para pesquisadores que aspiram abranger e tencionar seus campos de estudos, principalmente os localizados na região caribenha. Sua atualidade e rigor metodológico fazem da coletânea uma ferramenta importante para compreensão do Haiti, se estendendo como contribuição para antropologia contemporânea de forma geral, e, principalmente, para todos que objetivam descolonizar a produção de pesquisas e conhecimentos.

sobre a autora

\begin{abstract}
Aline Correia Antonini
Mestra em Antropologia pelo Programa de Pós-Graduação em Antropologia Social da Universidade Federal do Mato Grosso do Sul. É graduada em Turismo pela Universidade para o Desenvolvimento do Estado e da Região do Pantanal.
\end{abstract}

Recebido em: 28/10/2020

Aceito para publicação em: 22/12/2020 